\title{
Distribution of hygiene kits during a cholera outbreak in Kasaï-Oriental, Democratic Republic of Congo: a process evaluation
}

Lauren D'Mello-Guyett ${ }^{1,2^{*}}$ (D), Katie Greenland', Sharla Bonneville ${ }^{3}$, Rob D'hondt', Maria Mashako ${ }^{3}$, Alexandre Gorski ${ }^{3}$, Dorien Verheyen ${ }^{3}$, Rafael Van den Bergh ${ }^{4}$, Peter Maes ${ }^{2}$, Francesco Checchi ${ }^{5}$ and Oliver Cumming ${ }^{1}$

\begin{abstract}
Background: Cholera remains a leading cause of infectious disease outbreaks globally, and a major public health threat in complex emergencies. Hygiene kits distributed to cholera case-households have previously shown an effect in reducing cholera incidence and are recommended by Médecins Sans Frontières (MSF) for distribution to admitted patients and accompanying household members upon admission to health care facilities (HCFs).

Methods: This process evaluation documented the implementation, participant response and context of hygiene kit distribution by MSF during a 2018 cholera outbreak in Kasaï-Oriental, Democratic Republic of Congo (DRC). The study population comprised key informant interviews with seven MSF staff, 17 staff from other organisations and a random sample of 27 hygiene kit recipients. Structured observations were conducted of hygiene kit demonstrations and health promotion, and programme reports were analysed to triangulate data.

Results and conclusions: Between Week (W) 28-48 of the 2018 cholera outbreak in Kasaï-Oriental, there were 667 suspected cholera cases with a 5\% case fatality rate (CFR). Across seven HCFs supported by MSF, 196 patients were admitted with suspected cholera between W43-W47 and hygiene kit were provided to patients upon admission and health promotion at the HCF was conducted to accompanying household contacts 5-6 times per day. Distribution of hygiene kits was limited and only $52 \%$ of admitted suspected cholera cases received a hygiene kit. The delay of the overall response, delayed supply and insufficient quantities of hygiene kits available limited the coverage and utility of the hygiene kits, and may have diminished the effectiveness of the intervention. The integration of a WASH intervention for cholera control at the point of patient admission is a growing trend and promising intervention for case-targeted cholera responses. However, the barriers identified in this study warrant consideration in subsequent cholera responses and further research is required to identify ways to improve implementation and delivery of this intervention.
\end{abstract}

Keywords: Cholera, Outbreaks, Emergency, Water, Sanitation, Hygiene, Process evaluation

\footnotetext{
* Correspondence: lauren.dmello-guyett@lshtm.ac.uk

${ }^{1}$ Faculty of Infectious and Tropical Diseases, London School of Hygiene and

Tropical Medicine, London, UK

${ }^{2}$ Environmental Health Unit, Médecins Sans Frontières, Brussels, Belgium

Full list of author information is available at the end of the article
}

(c) The Author(s). 2020 Open Access This article is licensed under a Creative Commons Attribution 4.0 International License, which permits use, sharing, adaptation, distribution and reproduction in any medium or format, as long as you give appropriate credit to the original author(s) and the source, provide a link to the Creative Commons licence, and indicate if changes were made. The images or other third party material in this article are included in the article's Creative Commons licence, unless indicated otherwise in a credit line to the material. If material is not included in the article's Creative Commons licence and your intended use is not permitted by statutory regulation or exceeds the permitted use, you will need to obtain permission directly from the copyright holder. To view a copy of this licence, visit http://creativecommons.org/licenses/by/4.0/ The Creative Commons Public Domain Dedication waiver (http://creativecommons.org/publicdomain/zero/1.0/) applies to the data made available in this article, unless otherwise stated in a credit line to the data. 


\section{Introduction}

Cholera is a diarrhoeal disease transmitted through faecal-oral routes and caused by the pathogenic bacteria Vibrio cholerae $\mathrm{O} 1$ and $\mathrm{O} 139$. It remains a leading cause of infectious disease outbreaks globally [1, 2], and a major public health threat in complex emergencies [3, 4]. The Democratic Republic of Congo (DRC) contributes an estimated 189,000 (5-14\%) of the annual estimated 1.3-4.0 million cholera cases worldwide [4] and is considered a hotspot for cholera transmission regionally [5-7]. Cholera has been endemic in DRC since 1978 [8], and repeated complex emergencies have contributed to regular outbreaks [8-10]. In 2018 alone, 28,332 cholera cases and 890 deaths were recorded [11].

Spatiotemporal analyses suggest that transmission is localised to the households of cholera cases and household contacts of cases have up to a 100-fold greater risk of infection than those outside of the household [12-14], with risk greatest during the first 7 days after onset of a case's symptoms [15-17]. Evidence demonstrates that within-household transmission (i.e. human-to-human transmission) of cholera occurs through shared drinking water [18], contaminated food [19] and caring for the ill, due to prolific shedding from symptomatic and asymptomatic cases which can continue up to 14 days after onset of symptoms [20]. Models also show that within-household transmission contributes more to the explosive nature of epidemics than transmission through in the community such as environment-to-human transmission from contaminated water sources [12, 21-23]. Household-level water, sanitation and hygiene (WASH) interventions targeting within-household may thus be important in combatting cholera outbreaks [24-26], and can align with casecentred strategies for effective disease control [27-29].

"Hygiene kits" are a household-level WASH intervention recommended for use during cholera outbreak responses and in other crises contexts [30-33]. Selection of hygiene kit contents differs between organisations but they typically include a jerrycan (e.g. 10 to 20 litres (L)) for water collection and storage, soap, point of use (POU) water treatment product/s (e.g. chlorine, filters and/or flocculant disinfectants) and a handwashing device (e.g. a 10-L bucket with tap). Some guidelines specify that hygiene kits should contain components in sufficient quantities for one month's use by an "average sized" household [31, 32], whereas others recommend the inclusion of other components (e.g. toothbrushes, menstrual hygiene management materials) appropriate for populations affected by other types of crises [33, 34]. Distribution of a hygiene kit to a cholera cases when they are admitted to a Cholera Treatment Centre (CTC) or Cholera Treatment Unit (CTU) has been recommended in the Médecins Sans Frontières (MSF) guidelines "Management of a Cholera Epidemic" since 2017 [30]. This is based on previous research which found that the distribution of hygiene kits, or their component parts $[24,35]$, were effective in reducing cholera transmission in Bangladesh [25] and Haiti [36], and the burden of other diarrhoeal diseases [37-39]. However, hygiene kit distribution in outbreak response has not been widely published and is not common in cholera outbreaks [24, 40-42], due in part to a lack of evidence on effectiveness [24,43], transferability and scalability across contexts [40].

Hygiene kit distribution, like many public health interventions, is a complex intervention featuring several interacting components, and their effectiveness may vary across populations, settings and delivery modalities [4446]. Process evaluations of complex interventions are increasingly conducted to help explain observed outcomes in intervention studies [47-51] and envision whether the intervention will achieve its intended effects in other contexts or scales [51,52]. The process evaluation framework also allows implementation and change processes to be explored [47], the utility of theories underpinning intervention design such as hygiene kit distribution from health care facilities (HCFs) to be examined [53] and questions or hypotheses for future research to be generated. To date there have been no published process evaluations of the deployment of hygiene kits in cholera outbreaks.

We adapted conventional process evaluation methods developed for use in health impact trials to evaluate the distribution of hygiene kits by MSF during a cholera outbreak response in Kasansa district, Kasaï-Oriental province, DRC. This process evaluation ran in parallel with a prospective cohort study to assess the effect of the intervention on cholera incidence among household contacts of admitted cholera cases which will be published at a later date. This process evaluation sought to identify the successes and barriers of the hygiene kit distribution strategy for cholera control in order to understand delivery, use and scalability, and to propose recommendations to optimise future programmes. Three evaluation domains were explored including the implementation of the intervention, participants' responses to the intervention and the context in which it was delivered.

\section{Methods}

\section{Epidemiology of cholera in Kasansa, Kasaï-oriental}

The DRC Programme National d'Elimination du Choléra et de Lutte contre les autres Maladies Diarrhéiques (PNECHOL-MD), or National Program for the Elimination of Cholera and other Diarrhoeal Diseases, issued a country-wide alert of one laboratory confirmed cholera case in Kasansa district, Kasaï-Oriental province, DRC, 
on 9th August 2018 (Epidemiological Week 28 (W28)) $[54,55]$. A second alert and call for assistance came from the PNECHOL-MD in W34 [56-59].

Between W28-42, there were 443 suspected cholera cases and 29 deaths across Kasansa. MSF joined in W43, 16 weeks after the first laboratory-confirmed case, for 5 weeks between 22nd October to 23rd November 2018 (W43-47). A further 224 suspected cholera cases and 3 deaths occurred between W43-47 [55, 56, 58-66]. There was a high overall case fatality ratio (CFR) of $5 \%$ and Attack Rate (AR) of 0.28\% between W28-47 [66].

\section{Study setting and timeline of response}

In 2018 , there were an estimated 230,000 people living in Kasansa across 18 communities (Aires de Santé) [54]. Kasansa is a relatively homogeneous district in terms of socioeconomic composition of the population and agriculture-based income, and the local government had limited resources for health care [59, 65]. A high burden of cholera with high CFR had been observed throughout 2017 and 2018 across Kasaï-Oriental [9, 11, 67], and MSF had responded to other outbreaks earlier in 2018 [68]. Aside from MSF, there were few other public health programmes operating in Kasansa. Other nongovernmental organisations (NGOs) and government programmes included hygiene education, malnutrition awareness and malaria prevention.

The cholera response in Kasansa was led by the Ministry of Health (MoH). MSF supported seven government HCFs, two CTUs and five Oral Rehydration Points (ORPs) to provide case management, essential medicine supply, enhanced surveillance, community-level health promotion, and infrastructure improvements. Due to a high CFR and low attendance at HCFs by cases [54, 56, 66], outreach community health workers (CHWs) and an ambulance were deployed from W43. A total of 196 suspected cholera cases $(75 \%$ of total reported suspected cases) were admitted across all seven MSF-supported HCFs (121 in CTUs and 75 in ORPs) between W43-47. Hygiene kits were distributed with health promotion messaging to cholera patients admitted to the two MSFsupported CTUs, but not to patients at the ORPs, from W44-46 (Fig. 1).

\section{Theory of change}

Hygiene kit distribution was one component of the overall cholera response and a Theory of Change (ToC) was developed to provide a framework for the study (Fig. 2). Figure 2 shows how the effectiveness of the hygiene kit to reduce transmission of cholera among household contacts of cases and overall cholera incidence (Impact) may be influenced by factors along the ToC, beginning with i) national and local emergency preparedness supplies and the supply and delivery of hygiene kits to the intervention site (Inputs); which in turn determines ii) adequate health promotion, hygiene kit demonstrations in the CTUs and timely distribution of the kits to the target population at the point of admission (Activities); which leads to iii) the target population understanding the health promotion and hygiene kit demonstrations delivered at the CTUs and intending to take the kits home as soon as possible (Outputs); and finally, iv) intervention recipients who are motivated and have the ability to practice the target WASH behaviour/s

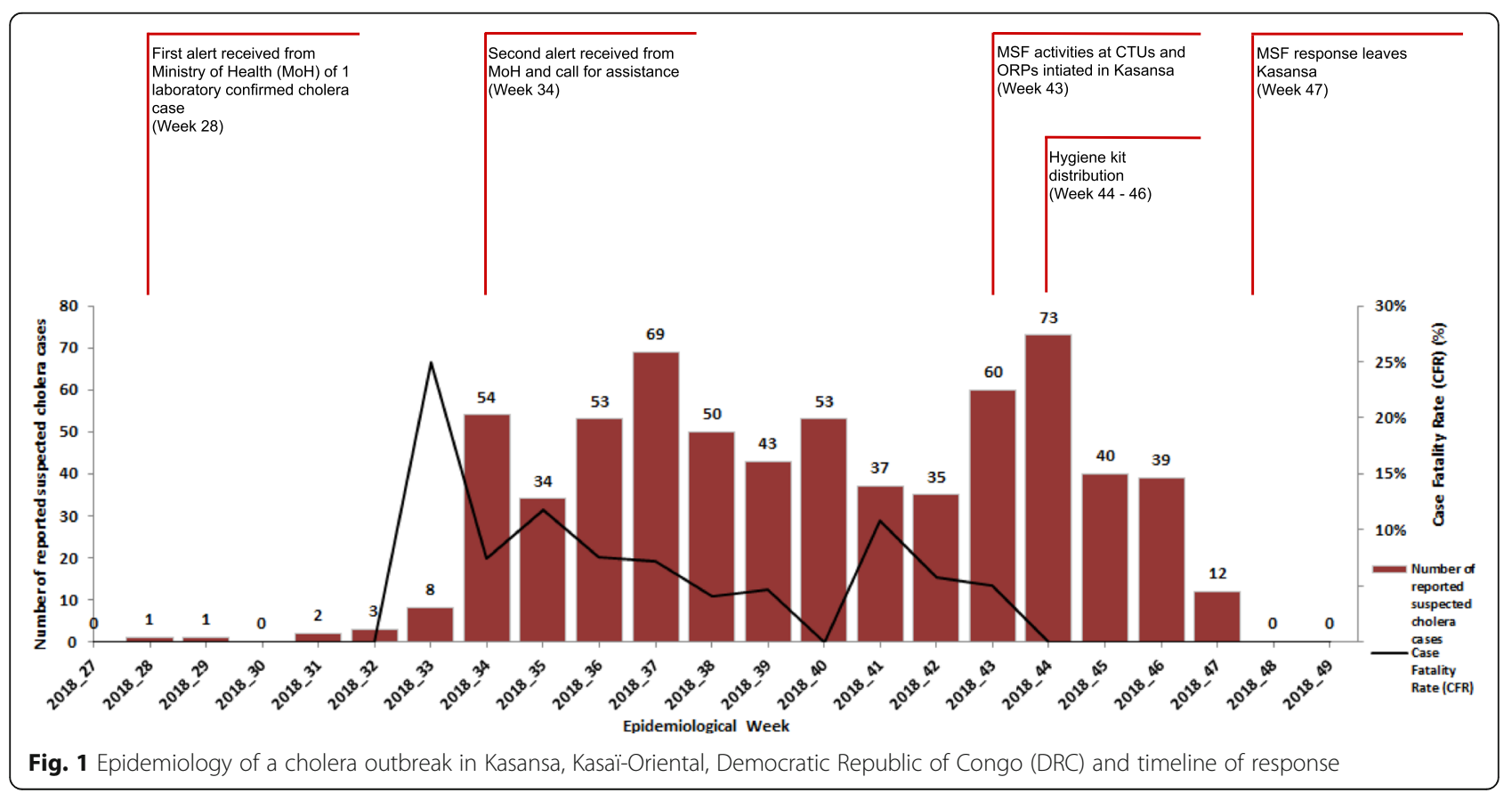




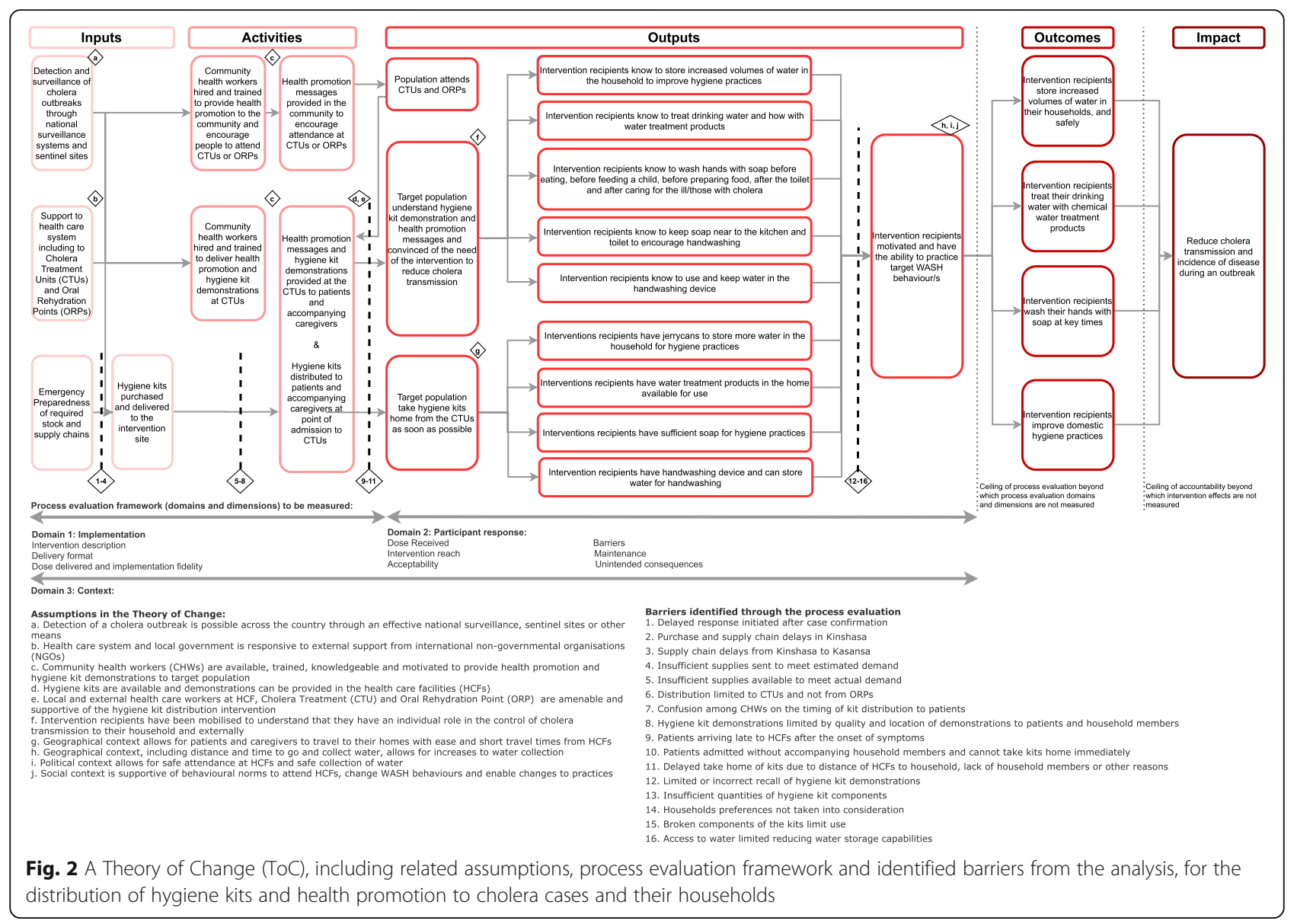

(Outputs \& Outcomes). Other factors and assumptions that needed to hold true for change to occur as predicted are also illustrated in the ToC.

\section{Process evaluation framework}

A process evaluation framework, including the domains, dimensions, research questions and data collection methods (Table 1), was developed using the process evaluation literature $[47,49,52,69]$, as well as relevant published applications in public health $[70,71]$ together with complex system theory [53]. Accordingly, this mixed methods study included quantitative measures of intervention activities and qualitative exploration of the interaction between the three domains of intervention implementation, participant response to the intervention, and the context that mediated this relationship. The domain of intervention context was populated according to seven established "pillars" (geographical, political, ethical, legal, epidemiological, socio-cultural, and socio-economic structures) and at the macro (i.e. national systems and structures), meso (i.e. institutional and community) and micro (i.e. participants and local surroundings) levels, according to models developed in the literature $[49,50,72]$.

\section{Data collection}

Most data collection was prospective, pre-specified and collected during and immediately following the MSF response, between October-December 2018 (W43-52). Some data, including intervention reports and additional surveillance data, were collected post-hoc between December 2018-February 2019 (W52-9).

The evaluation team comprised five experienced Congolese enumerators, all of whom held Bachelor's degrees and were MSF staff, partnered with five local less-experienced Congolese enumerators from KasaïOriental, who had up to secondary level education and were hired on temporary contracts for the study period. All data collection was conducted with assistance from two female international investigators (one British and one Canadian), both of whom had Master's degrees. Prior to data collection, a five-day training was led by the two international investigators in Kinshasa to introduce the study, methods, ethics of research and to pilot all data collection tools. A twoday training was provided to the local Congolese enumerators at the study site. The evaluation team were MSF staff and study participants knew of the researchers' affiliations to the organisation. The 
Table 1 Process evaluation framework: domains, dimensions, study population, data sources and data types

\begin{tabular}{lllll}
\hline Process & Research question & Core information sought & Study population & \\
evaluation & & & \\
domains and & & & \\
dimensions & &
\end{tabular}

\section{Domain 1: Implementation}

1. Intervention a. What was the design Overall design of the description of the intervention? intervention including site, population, health care facility and structure, rationale and timeline

b. What are the components of the intervention?

Content of the intervention including the intervention components and selection

$\begin{array}{ll}\text { 2. Delivery } & \text { Where and when was } \\ \text { format } & \text { the intervention } \\ \text { delivered? }\end{array}$

What other interventions (WASH and non-WASH) were provided by MSF?

What other agencies were involved in implementation?

How was the intervention demonstrated and explained to users?

What resources were used to implement the intervention?

$\begin{array}{ll}\text { 3. Dose } & \text { How many } \\ \text { delivered and } & \text { interventions were } \\ \text { implementation } & \text { delivered? } \\ \text { fidelity } & \text { Was the intervention } \\ & \text { delivered as planned? }\end{array}$

\section{Domain 2: Participant response}

4. Dose received How many interventions were received?

5. Intervention How many people reach
Description of targeted area, MSF staff, local government population size, health care facility structure and and national agencies (e.g. WASH and health clusters, environment, and timeline of PNECHOL-MD) the intervention

Documentation of other interventions locally and nationally including the number of "competing" programmes, or components reaching the target population

Documentation of the other agencies and government structures operating in the targeted area, including their roles and perceptions on the intervention

Documentation of the delivery format, timing and interaction with intervention recipients

Human, material and and other organisations (e.g. Save The Children, UNICEF, Solidarities International, Catholic Relief Services, Action Aid)

MSF staff, local government and other organisations

SSIs and intervention reports

Qualitative/ Quantitative

MSF staff, local government and other organisations

SSIs and intervention reports

Qualitative

MSF staff (e.g. CHWs)
MSF staff \& intervention
recipients
MSF staff, local government
and other organisations

Structured observations

Qualitative/ Quantitative

Qualitative

SSIs, intervention reports,

Qualitative/ financial resources utilised by the intervention

Number of interventions delivered and number of planned interventions

Documentation of the content, quality, successes and challenges of the intervention delivered

MSF staff \& intervention recipients

Number of interventions received in the households of recipients

Number of people in the household who interacted
Intervention recipients

SSIs

Qualitative

Intervention recipients activity records and

surveillance data

SSIs and intervention reports

Quantitative

Qualitative/
Quantitative

$$
\text { Quantitative }
$$

MSF staff, local government

SSIs and intervention reports
Semi-structured interviews

Qualitative/

Quantitative

Qualitative/

Quantitative reports and surveillance data rom the local \& national eoreferenced maps urchase orders, distribution
Qualitative

.


Table 1 Process evaluation framework: domains, dimensions, study population, data sources and data types (Continued)

\begin{tabular}{|c|c|c|c|c|c|}
\hline $\begin{array}{l}\text { Process } \\
\text { evaluation } \\
\text { domains and } \\
\text { dimensions }\end{array}$ & Research question & Core information sought & Study population & Data source & Data type \\
\hline & $\begin{array}{l}\text { intervention? And their } \\
\text { uptake of the } \\
\text { intervention? }\end{array}$ & $\begin{array}{l}\text { with the intervention and } \\
\text { use }\end{array}$ & & & \\
\hline 6. Acceptability & $\begin{array}{l}\text { What were the levels of } \\
\text { participation and } \\
\text { satisfaction? }\end{array}$ & $\begin{array}{l}\text { Comprehension of } \\
\text { emotional responses to the } \\
\text { intervention, acceptability of } \\
\text { the intervention and } \\
\text { component preferences }\end{array}$ & Intervention recipients & SSIs & Qualitative \\
\hline 7. Barriers & $\begin{array}{l}\text { What were the barriers } \\
\text { to using the } \\
\text { intervention? }\end{array}$ & $\begin{array}{l}\text { Obstruction (physical and/or } \\
\text { emotional barriers) to the } \\
\text { intervention and concerns } \\
\text { with the intervention }\end{array}$ & $\begin{array}{l}\text { Intervention recipients, MSF } \\
\text { staff, local government and } \\
\text { other organisations }\end{array}$ & SSls & Qualitative \\
\hline 8. Maintenance & $\begin{array}{l}\text { How and why was the } \\
\text { intervention sustained } \\
\text { over time (or not)? }\end{array}$ & $\begin{array}{l}\text { Retention of key messages, } \\
\text { target behaviours and } \\
\text { reflections of the } \\
\text { intervention }\end{array}$ & Intervention recipients & SSIs & $\begin{array}{l}\text { Qualitative/ } \\
\text { Quantitative }\end{array}$ \\
\hline $\begin{array}{l}\text { 9. Unintended } \\
\text { consequences }\end{array}$ & $\begin{array}{l}\text { What effects were not } \\
\text { captured or were there } \\
\text { unexpected outcomes, } \\
\text { both related to the } \\
\text { intervention and } \\
\text { unrelated care? }\end{array}$ & $\begin{array}{l}\text { Reasons for any deviation } \\
\text { from the intended activities, } \\
\text { interaction with and use of } \\
\text { the intervention }\end{array}$ & $\begin{array}{l}\text { Intervention recipients, MSF } \\
\text { staff, local government and } \\
\text { other organisations }\end{array}$ & SSIs & Qualitative \\
\hline \multicolumn{6}{|c|}{ Domain 3: Context } \\
\hline \multirow[t]{2}{*}{ Context } & What was the context? & $\begin{array}{l}\text { Characteristics of the delivery } \\
\text { context (geographical, } \\
\text { political, legal, ethical, } \\
\text { epidemiological, } \\
\text { sociocultural, socioeconomic) }\end{array}$ & $\begin{array}{l}\text { MSF staff, local government } \\
\text { and other organisations }\end{array}$ & $\begin{array}{l}\text { SSIs, intervention reports, } \\
\text { activity records and budgets }\end{array}$ & Qualitative \\
\hline & $\begin{array}{l}\text { What external factors } \\
\text { affected the } \\
\text { implementation and } \\
\text { the outcome? }\end{array}$ & $\begin{array}{l}\text { Organisational context: } \\
\text { culture, agenda, priorities, } \\
\text { leadership styles and } \\
\text { perceptions of leaders, } \\
\text { perceptions on research and } \\
\text { evaluation, and other } \\
\text { contextual factors }\end{array}$ & $\begin{array}{l}\text { MSF staff, local government } \\
\text { and other organisations }\end{array}$ & SSIs and intervention reports & Qualitative \\
\hline
\end{tabular}

CHWs Community Health Workers, MSF Médecins Sans Frontières, PNECHOL-MD Programme National d'Elimination du Choléra et de Lutte contre les autres Maladies Diarrhéiques, SSIs Semi-structured interviews, WASH Water, sanitation and hygiene

evaluation team was not involved in the design or implementation of the intervention.

All tools were written in English, translated to French, piloted and translated to the local language, Tshiluba. The study is reported in accordance with the COREQ checklist for qualitative studies [73]. Specific data collection methods are described below and summarised in Table 1.

\section{Semi-structured interviews and observations}

Five Congolese enumerators conducted semi-structured interviews (SSIs) between W45-47 at households of a simple random sample of households enrolled in the parallel prospective cohort study who received a hygiene kit at an MSF-supported CTU. These SSIs lasted approximately $30 \mathrm{~min}$ and followed a topic guide including reported and observed measures of hygiene kit use to explore the participant response domain. SSIs with households were conducted until perceived data saturation.

SSIs with a purposive sample of MSF and non-MSF "implementers" were also conducted by three enumerators (one Congolese, one Canadian and one British) between W43-48, also until saturation. Implementers conducting activities in the study site were informed of the study in advance and requested to participate in SSIs. SSIs followed another topic guide to explore the implementation and context domains. Interviews were conducted for 30-45 min in participants' offices or at the CTUs.

\section{Structured observations}

Two Congolese enumerators conducted weekly unannounced visits to the two CTUs to observe hygiene kit 
demonstrations and health promotion sessions. A structured form was used to record details about the implementation and participant response domains.

\section{Intervention reports, activity records and budget}

A total of 34 intervention documents were collected from implementers, local government and other organisations. Details of the strategy and description of the interventions were checked against guidelines [30], equipment catalogues [74] and internal policy documents. Attendance at hygiene kit demonstrations and health promotion sessions, and hygiene kit distribution lists were all recorded. Surveillance data were collected from the local and national government to describe the epidemiological context of the intervention. Any details of implementation and context domains were extracted from these reports.

\section{Data management and analysis}

SSI data were collected on tablets through the KOBO Toolbox platform (Harvard Humanitarian Initiative, Cambridge, MA, USA), which allows a combination of quantitative questions and audio recordings of the interviews. Field notes were also taken throughout the interview by the enumerators. Transcriptions from the audio recordings and field notes were made in MS Word (Microsoft, Redmond, VA, USA). Data from structured observations were collected on paper forms and transcribed to MS Excel (Microsoft, Redmond, VA, USA).

Quantitative data from surveillance, intervention documents and structured observations were entered into MS Excel to form a single dataset for analysis. Data on the implementation and receipt were cleaned and analysed in Stata 15 (StataCorp, College Station, TX, USA).

Qualitative analysis from the SSI transcriptions, structured observations and intervention documents was conducted in NVivo 11 (QSR International, Doncaster, Victoria, Australia) and analysis was based on thematic content analysis [75, 76] and example papers [69]. Following an iterative process to analyse the data, data were coded deductively according to the pre-specified domains and dimensions of our process evaluation framework.

\section{Results}

\section{Description of study participants}

Household SSIs featured 27 respondents (13 female; average age 43 years). All respondents were married with four children on average, and up to 22 people lived in their households. No household refused to participate in the study. All respondents were engaged in agriculture and/or artisanal diamond mining. None of the respondents had themselves been admitted to a CTU or ORP and all were relatives of the admitted case.
SSIs were conducted with 17 implementers (seven MSF, four local government and six from NGOs), three of whom were female. No implementer or organisation refused to participate. Implementers from MSF and NGOs had on average 3 years of experience in cholera outbreaks, and over 5 years working with NGOs. Government respondents had less than a year working in cholera outbreaks, and over 5 years of experience working in government.

\section{Process evaluation findings}

Following indexing of findings, a narrative was synthesised for each domain and dimension of the process evaluation. Table 2 presents illustrative quotations and are cited in the text. Barriers to intervention implementation and participant response are indicated below by numbers in square brackets e.g. [Barrier 1] and mapped back onto the ToC (Fig. 2).

\section{Domain 1: implementation Intervention description}

Each cholera case and their accompanying household received a hygiene kit containing a $1 \mathrm{~kg}$ bar soap; $60 \mathrm{sa}$ chets of flocculant disinfectant (P\&G Purifier of Water ${ }^{\mathrm{Tw}}$, Procter \& Gamble and Centers for Disease Control and Prevention, Pakistan) or 120 chlorine tablets (Aquatabs ${ }^{\mathrm{Tw}}$, Medentech, Wexford, Ireland) estimated to be sufficient to treat 20-L of water per day for 30 days; a handwashing device of a 10-L bucket with tap and lid; and, a 20-L jerrycan. The appropriate water treatment product provided was determined based on the water source reportedly used by the household (flocculant-disinfectant for generally turbid open surface water sources; chlorine disinfectant for protected sources). Hygiene kits were distributed by local, MSF-trained CHWs to patients and their accompanying household members at the CTUs, with hygiene kit demonstrations provided 5-6 times per day.

\section{Delivery format}

The response was initiated midway through the cholera outbreak [Barrier 1] and quantitative findings indicated that hygiene kits distribution was limited to W44-46 [Barrier 2]. Access and delivery of interventions to remote populations came with steep financial costs and required an influx of non-local staff and supplies, as mentioned in qualitative interviews with implementers (Quotation 1) [Barrier 3 \& 4].

Most hygiene kits were distributed on the day of admission (71\%), with the remainder 1-3 days after [Barrier 7]. Between W44-46, 131 hygiene kit demonstrations and health promotion sessions were attended by 749 people at the two CTUs. Structured observations suggested good adherence of the demonstrations to 
Table 2 Illustrative quotations from hygiene kit recipients and programme implementers from a cholera outbreak in Kasansa, KasaiOriental, Democratic Republic of Congo

\begin{tabular}{|c|c|c|}
\hline Process evaluation dimension & $\begin{array}{l}\text { Quotation } \\
\text { Number }\end{array}$ & Quotation \\
\hline \multirow[t]{2}{*}{ Delivery format } & 1 & $\begin{array}{l}\text { "The cholera programmes are challenging from logistics point of view. In Mbuyi Mayi [provincial capital], } \\
\text { it's not possible to find P\&G Purifier of Water" and Aquatabs }{ }^{T M} \text {. So, everything comes from Goma or } \\
\text { Kinshasa. All of our staff come from Goma or Kinshasa. And our money does too- we are waiting for } \\
\text { people to make signatures on the delivery of products and money to pay local RECOs [community health } \\
\text { workers]." } \\
\text { - Respondent \#12, female }\end{array}$ \\
\hline & 2 & $\begin{array}{l}\text { "It was loud in the CTU, and new patients were always arriving. Because it was small, there was not a big } \\
\text { space for the demonstrations. The RECO [community health workers] also had to repeat parts many } \\
\text { times. Sometimes there were differences between sessions." } \\
\text { - Respondent \#2, male }\end{array}$ \\
\hline \multirow[t]{2}{*}{$\begin{array}{l}\text { Dose delivered and } \\
\text { implementation fidelity }\end{array}$} & 3 & $\begin{array}{l}\text { "At the beginning, I gave the kit to the cases who had confirmed cholera. Then I gave them to all the } \\
\text { patients. But some patients had no family. I had to give directly to the patient." } \\
\text { - Respondent \#3, female }\end{array}$ \\
\hline & 4 & $\begin{array}{l}\text { "In the intervention, we gave the kits at admission. But this was not happening at the beginning. At the } \\
\text { beginning, I gave the kit to the cases who had confirmed cholera .... At the end I was giving them to } \\
\text { everyone at admission to the CTU." } \\
\text { - Respondent \#3, female }\end{array}$ \\
\hline \multirow[t]{2}{*}{$\begin{array}{l}\text { Dose received, reach and } \\
\text { acceptability }\end{array}$} & 5 & $\begin{array}{l}\text { "Our water source is far away and has a lot of sediment, maybe } 45 \mathrm{~min}, \text { I walk. And the filter valve } \\
\text { provided to filter the water does not easily pass water especially when the water is dirty from the river. It } \\
\text { takes a long time to filter." } \\
\text { - Respondent \#21, female }\end{array}$ \\
\hline & 6 & $\begin{array}{l}\text { "If I have the necessary means and enough, I will buy kits for my wives, but the lack of money makes it } \\
\text { difficult. I have } 3 \text { wives in three separate houses and there are not buckets to share." } \\
\text { - Respondent \#24, male }\end{array}$ \\
\hline \multirow[t]{3}{*}{ Barriers to intervention use } & 7 & $\begin{array}{l}\text { "Yes, I need several more elements than just the hygiene kit. I would like some foufou (maize flour), milk, } \\
\text { clothes for the family, land my children need money to support school." } \\
\text { - Respondent \#21, male }\end{array}$ \\
\hline & 8 & $\begin{array}{l}\text { "So, we have no measure of impact for the kits we planned gave out. We need to conduct post distribution } \\
\text { monitoring to see what has been used in kits and to also check precisely on the diversity of use. Some of } \\
\text { the utensils of the kit including the bucket with tap served as storage of things rather than handwashing } \\
\text { bucket. We also need to check if supplies need to be redistributed." } \\
\text { - Respondent \#5, male }\end{array}$ \\
\hline & 9 & $\begin{array}{l}\text { "So, I have the feeling that all of us are doing really short interventions, like the distribution of Aquatabs }{ }^{\top M} \text {, } \\
\text { P\&G Purifier of Water" chlorination points. But the biggest challenge here is the lack of water. So, we were } \\
\text { discussing also with the Hub, the WASH Cluster in Kasaï-Oriental today and also, he was thinking that } \\
\text { maybe would have been better to focus funding durable solutions. So yes, it's true that there is the need } \\
\text { now but maybe now that the cholera cases are reducing, we would be better looking at...maybe...financing } \\
\text { new water points or chlorination points for } 2 \text { months. We could decide to rehabilitate the existing } \\
\text { infrastructure or having, in this case, huge funding for rehabilitating the water gravity scheme that is here." } \\
\text { - Respondent \#12, male }\end{array}$ \\
\hline
\end{tabular}

hygiene kit contents, described in Table 3, and that these were well received by the population and involved participants attending the CTUs. However, demonstrations were often interrupted by noise and other distractions (Quotation 2) [Barrier 8].

\section{Dose delivered and implementation fidelity}

MSF estimated 250 kits would be required for the response, but only 165 kits were delivered to Kasansa. This was insufficient for the 196 patients admitted between W43-47 [Barriers 4 \& 5]. Moreover, quantitative findings indicated only 79 admissions, or their accompanying household members, received a hygiene kit, namely $52 \%$ of the 153 admissions across all seven HCFs during the period when hygiene kits were available between W44-46 or $40 \%$ of the 196 suspected cases admitted to MSFsupported facilities between W43-47 (Fig. 3). The 86 unused kits were donated to local government when MSF left Kasansa.

Reasons given by implementers for the low coverage included the late arrival of the kits to the project site [Barriers 1-3]; CHWs only distributing kits from the two CTUs and not the five ORPs [Barrier 6]; patients without accompanying household members which caused confusion as to whom the kit should be given [Barrier 10]; and, incorrect timing of distribution (i.e. giving kits at exit rather than at admission) which had to be re-emphasised multiple times to CHWs (Quotation 3 \& 4) [Barrier 7]. 


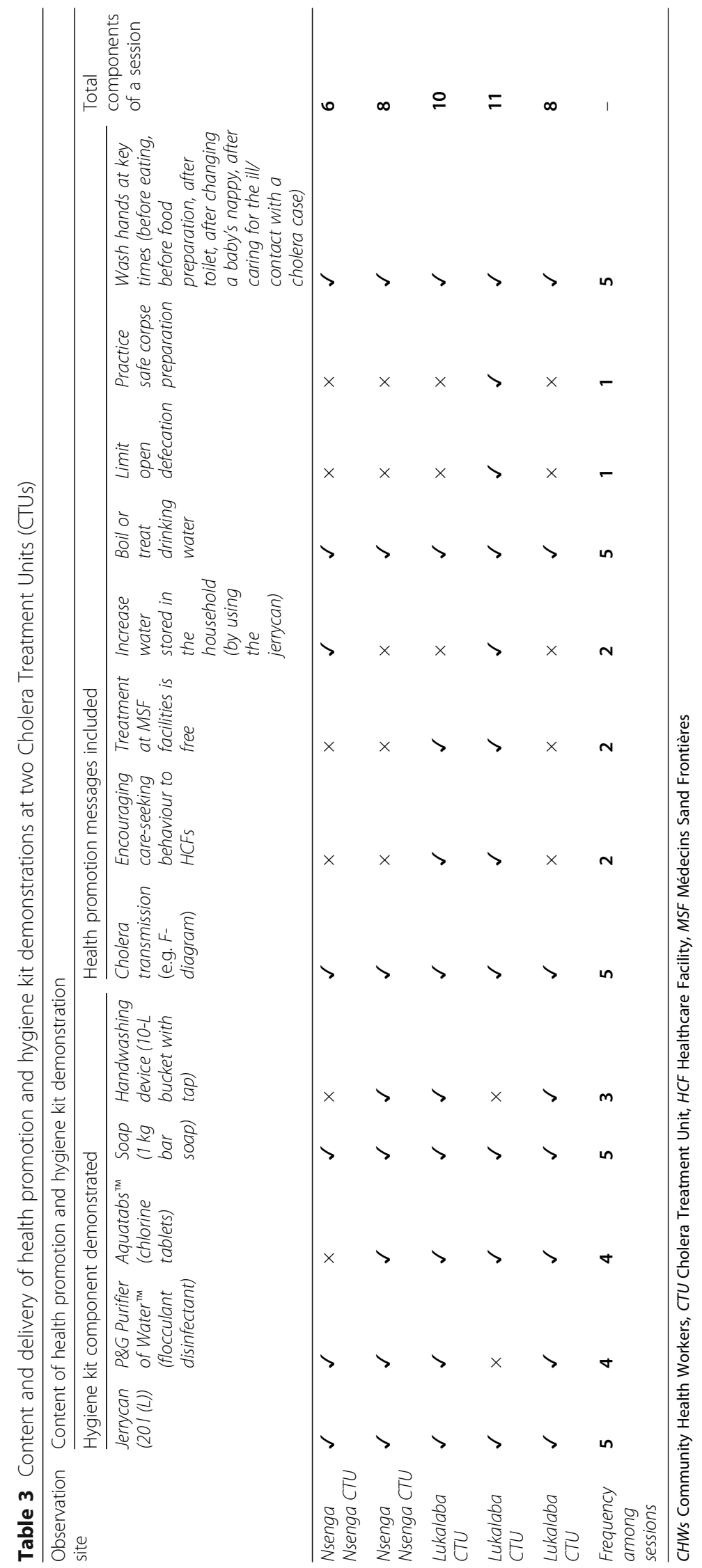




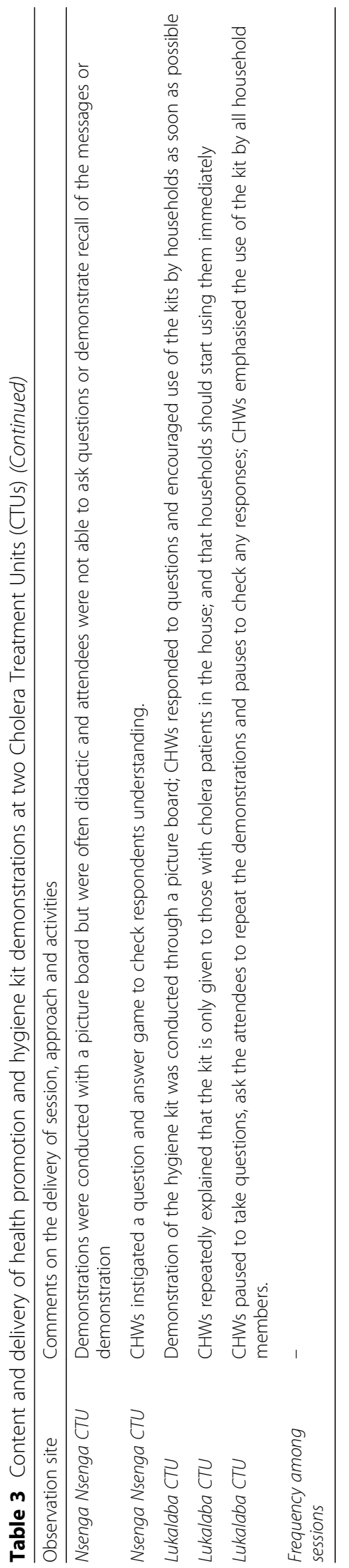




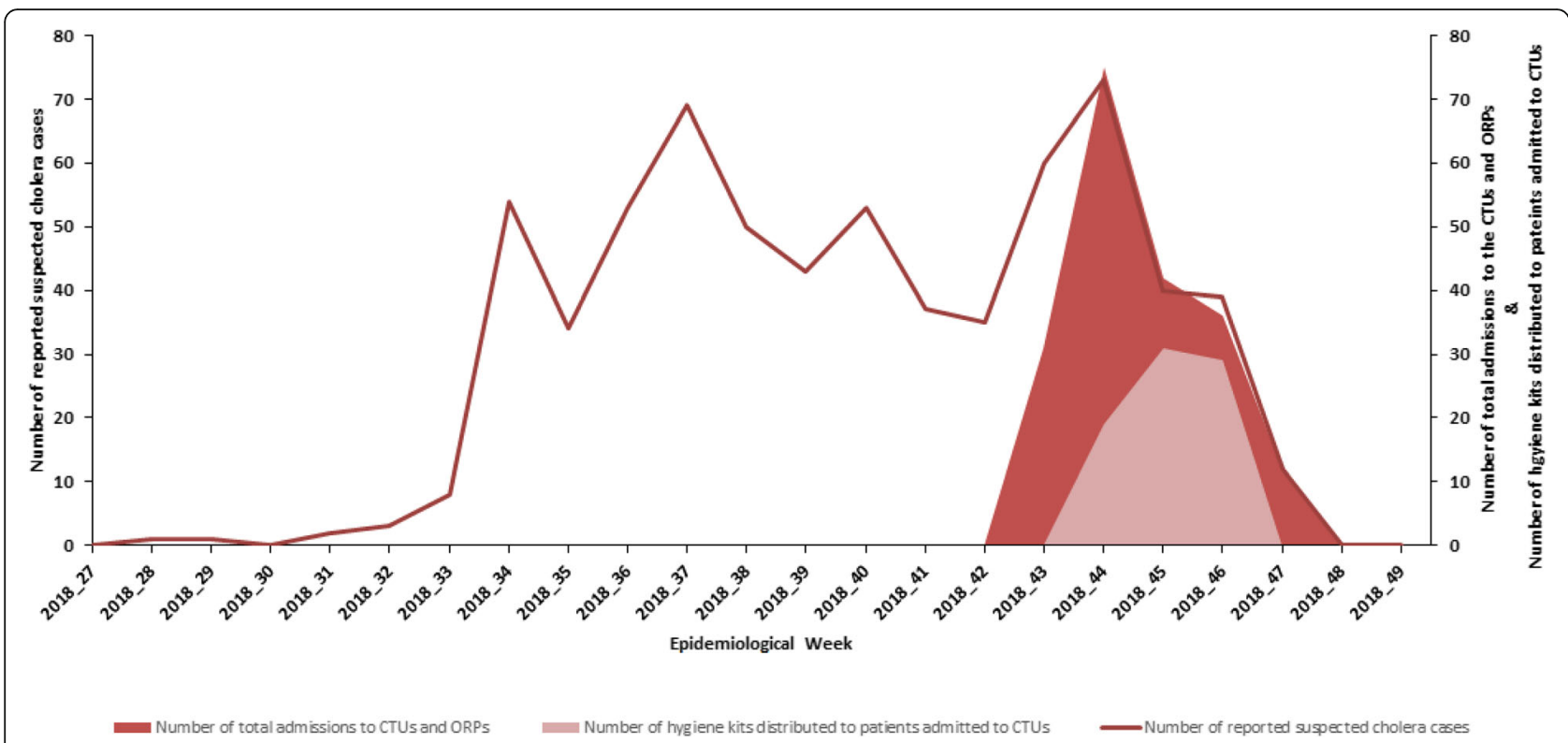

Fig. 3 Coverage of hygiene kits distributed to patients between Week 43-462,018 of a cholera outbreak in Kasansa, Kasaï-Oriental, DRC

\section{Domain 2: participant response}

\section{Dose received, reach and acceptability}

In interviews with intervention recipients, most regarded the intervention to be useful in their households, with preference for the soap and the handwashing device. It was reported by interviewees that they had not shared or sold any components. Distance to HCFs was selfreported as a barrier to seeking care by households, and the weight and size of the kit was cited as an issue when taking the kit home (Quotation 5) [Barrier 10]. Yet results indicate that, on average, patients arrived at the HCFs and were admitted within 1 day of the onset of symptoms (median 1 day, range 0-10 days) [Barrier 9], and all interviewed households reportedly brought the hygiene kit directly home within 3 days of kit receipt and within 7 days after the onset of symptoms (median 3 days, range 1-6 days) [Barrier 11].

All interviewed households attended a hygiene kit demonstration, and respondents reported that they understood how the kits should be used. This translated to self-reported changes in the targeted WASH behaviours among these households. Interviewed recipients reported using all components of the hygiene kit at varying frequencies. The handwashing device and jerry can were reportedly used two-to-three times per day whereas POU water treatment was used between once a day to three times a week. Recall of when and how to treat drinking water was frequently incorrect [Barrier 12] and self-reported adherence to POU water treatment was low.

The handwashing device and jerrycan were observed to be in use during household SSIs (i.e. water available in either container), and soap was both observed to be in use (i.e. visible bubbles, or visibly smaller in size) and located next to the handwashing device or cooking area. These practices mirrored the observed emphasis that CHWs placed on handwashing and use of soap in the hygiene kit demonstrations and health promotion provided at the CTUs (Table 3 ).

\section{Barriers to hygiene kit use}

An inadequate quantity of soap was the most cited barrier to using the hygiene kit, particularly among larger families as all households received the same quantity of soap irrespective of household size [Barrier 13]. Several interviewees from polygamous households reported that kits were either not shared among co-wives and respective dwellings or, if shared, that quantities were insufficient (Quotation 6). Similarly, one 20-L jerrycan for larger households was insufficient for their water storage needs, and households would have preferred a larger vessel (reported range 30-60-L). Other preferred items included money, more soap, food and clothes (Quotation 7) [Barrier 14].

Implementers from MSF, local government and other NGOs also felt that quantities were insufficient for average-sized households [Barrier 13], and repeated delivery would be required to facilitate effective disease control (Quotation 8). Many also felt that since the hygiene kit generally reduced risk of diarrhoeal diseases, households should be provided with enough materials to maintain use for longer than the outbreak. Implementers were also concerned that raising awareness of cholera and distribution of hygiene kits were limited actions, 
particularly when a population has only basic or limited access to water supply (e.g. river and surface water sources) (Quotation 9) [Barrier 16].

\section{Maintenance}

Sustained use of the hygiene kits was difficult among interviewed households. Most households reported that they were unable to continue using the kit beyond 2 to 3 weeks, rather than the intended 1 month [Barrier 13]. Some parts of the kit were broken such as the tap on the handwashing device [Barrier 15]. Enthusiasm to continue using the kit was high, although the availability of stored water and water inside the handwashing device was affected by distances and time to water supply. All households reported over $5 \mathrm{~km}$ distances to water sources [Barrier 16].

\section{Unintended consequences}

There were no unintended consequences of hygiene kit use reported among intervention recipients. However, among the general population there was tension between households who had attended the CTU and received a hygiene kit and households who had attended the ORPs and not received a hygiene kit. Additionally, there was no retroactive distribution of kits to patients admitted to
CTUs prior to the arrival of the hygiene kits. Households who lived close to admitted cholera cases but without admissions in their own households were anecdotally dissatisfied that they did not receive kits which could have led to discontent or stigmatisation of households with cholera cases.

\section{Domain 3: context}

Contextual events and influences unique to and across the macro, meso and micro levels were extracted from SSIs and intervention reports, conceptualised in Fig. 4, and supplement reported findings among the other domains and dimensions. Key examples of contextual factors affecting the implementation of and participant response to the intervention included: the limited surveillance leading to delayed response initiated after case confirmation [Barrier 1], the geographical context of limited access to WASH infrastructure and distances to water sources [Barrier 16]; the socioeconomic status of the population, which affected purchasing power and explains a preference for help with food and clothing in addition to hygiene kits [Barrier 14]; and the local political context which affected the limited resources available for cholera response programmes and lack of other actors available to respond.

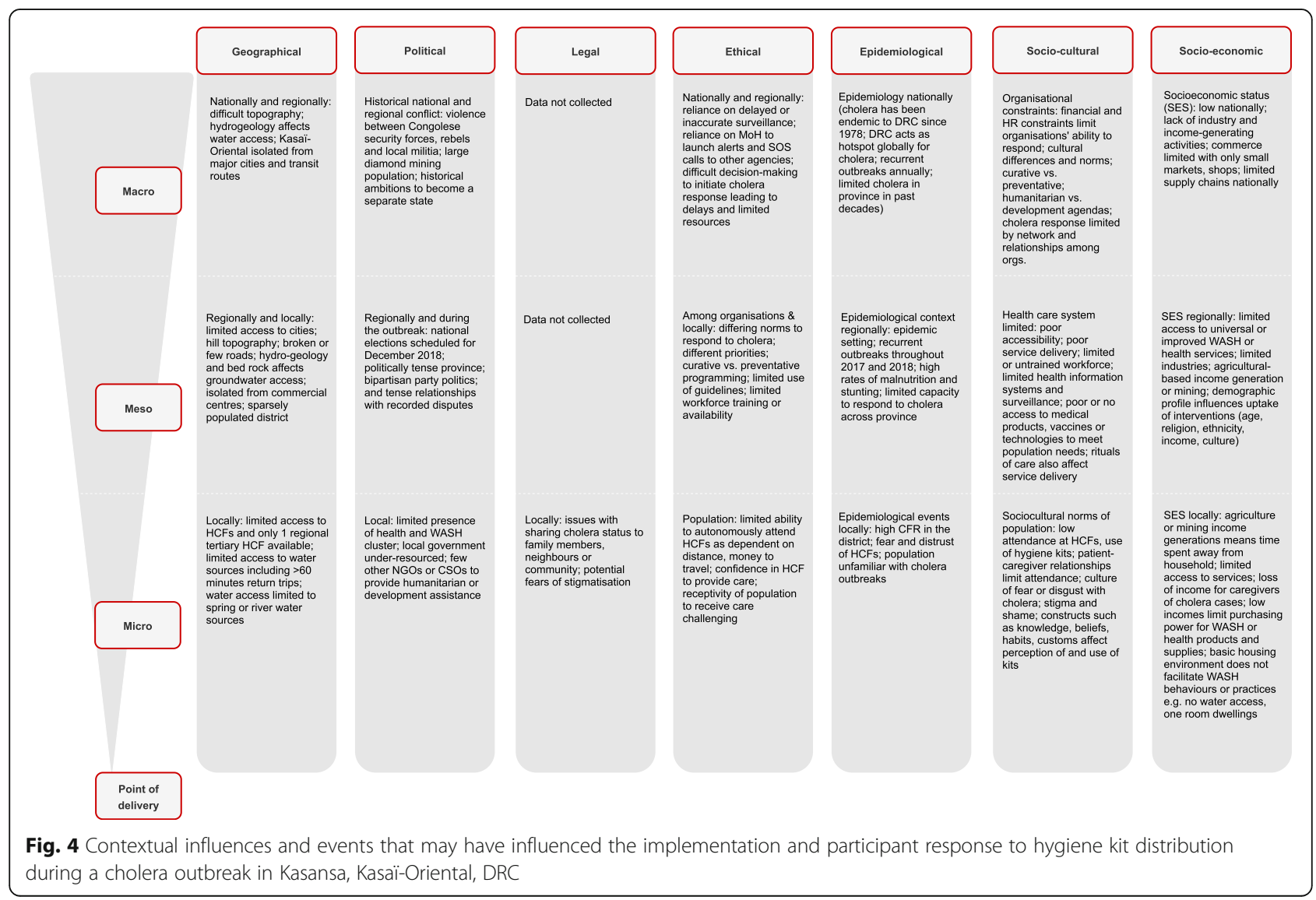




\section{Discussion}

This process evaluation of hygiene kit distribution during a cholera outbreak identified numerous barriers to effective implementation of and participant response to the intervention, and to our knowledge is the first published process evaluation of a cholera outbreak response by MSF. During the late-2018 cholera outbreak in Kasansa, Kasaï-Oriental, DRC, it was observed that only $52 \%$ of admitted suspected cholera cases received a hygiene kit intervention. Although the majority of admitted patients in receipt of a hygiene kit had received the intervention on the day of admission, the delay of the overall response, delayed supply of hygiene kits and insufficient quantities of hygiene kits available limited the intervention's coverage and utility, and may have diminished the effectiveness of the intervention. Overall, our process evaluation demonstrated that a large proportion of households either did not receive the kit or received the kit after the incubation period, or at least during the symptomatic period of the first case in the household, meaning that much of the infectiousness window from primary to secondary generation cholera cases within the household was not mitigated, nor would there be a reduction in the incidence of cholera among the population globally, as depicted in the ToC.

The analysis identified four key points in the ToC where barriers affected the implementation of and response to the hygiene kit intervention, and the ultimate reduction in cholera incidence and associated cholera morbidity and mortality (Fig. 2). In our case, the relative effect on within-household transmission will be reportedly separately in a parallel cohort study.

\section{Barriers to hygiene kit arrival at the project site}

The MSF response was delayed and launched 16 weeks into the outbreak, clearly diminishing any potential effect of a cholera outbreak response. Capacity to deliver the hygiene kits to the intervention site was largely lacking at the national level within MSF, and although hygiene kits are part of the emergency preparedness stocks in the capital city Kinshasa, insufficient quantities were delivered. This highlights the need for expansion of emergency preparedness supplies at the national level or regionally at other MSF project sites (e.g. in Kananga [77]) with a reliable supply chain and transport of standard components required in cholera responses [36, 78], as well as the need for market supply chain analysis in key sites nationally to increase the ability for local purchasing and supply [79].

\section{Barriers to hygiene kit distribution at the HCFs}

The distribution of hygiene kits was intended to target those households most at risk, but insufficient supplies and the decision to only distribute from CTUs and not the ORPs limited coverage and availability of the intervention to this population at risk. ORPs are typically located remotely and only provide rehydration to cases [30], however, they also may include 1-2 beds for case management and households may return home from these HCFs without attending the more centralised CTU or HCF. The exclusion of ORPs limited the intervention reach, and there is an opportunity to distribute hygiene kits to case-households from these HCFs and, in future responses, ORPs may need to be included for a more case-centred approach.

MSF guidelines specify that timely distribution is at admission [30]: CHW confusion on the timing of distribution had an effect on when kits were distributed, suggesting a need to reinforce the recommended delivery times in future trainings. The design of the hygiene kit demonstrations and health promotion should also be reflected upon to ensure the timely and sustained use of the hygiene kits in patient's homes, and overall WASH intervention uptake. Evidence has shown that more participatory and engaging approaches, instead of simple health messaging [80, 81], are also needed to motivate and increase households' ability to mount disease control efforts [69] and future programmes should adopt such frameworks.

\section{Barriers transferring hygiene kits to patient households}

In many cases, admission of suspected cases to HCFs came 0-3 days after the onset of symptoms, but timely presentation of cases at HCFs remains a major issue experienced in cholera outbreaks [82]. Interviewees reported that many cases arrived without accompanying household members and thus were impeded from taking kits directly home whilst they were admitted. The time delay from receiving the kit, distance of HCFs to households and burden of transferring the kit home (i.e. bulky to transport for long distances) limited prompt use. These factors in turn may diminish the ability of the hygiene kits to reduce transmission within the transmission window from cases to household contacts.

One potential solution could be to increase active case finding at the district level and employ more $\mathrm{CHWs}$ to encourage cases to attend and household members to accompany suspected cases to HCFs. Another option could be to deploy rapid response teams (RRTs) to directly deliver hygiene kits and other interventions (e.g. other WASH materials, oral cholera vaccination (OCV) or antibiotic prophylaxis) to case households and the surrounding population at risk [27-29, 78], especially in densely populated or urban settings [28]. However, expanding the coverage of an intervention beyond patient-centred delivery may not be feasible for some organisations and a wider case-area targeted intervention (CATI) approach may require intensive case 
identification, a highly mobile response and high financial resources.

\section{Barriers to hygiene kit use by households}

Recall of POU water treatment demonstrations was limited, and this may have curtailed the use or adherence to use of the Aquatabs ${ }^{\text {Tw }}$ chlorine tablets or P\&G Purifier of Water $^{\text {rx }}$ flocculant disinfectant, as observed in other studies [44, 83]. Additionally, there was a limited supply of consumables in the kits and larger households found it difficult to maintain use for longer than a few weeks. Cholera contamination in the household can be sustained whilst cases are shedding bacteria for up to 14 days after onset of symptoms [20], and maintained use of interventions is required to reduce transmission [84]. This questions the use of standardised kits for variable household sizes, and suggests the additional need for contextual adaptations to be made to WASH intervention design considering household sizes, preferences and cultural norms [85].

Lastly, the hygiene kit intervention was designed to target key within-household transmission routes by treating contaminating drinking water and enabling improved hygiene practices. However, the intervention relies on a reliable supply of water and in sufficient volumes to facilitate hygiene practices [86]. Water sources were limited amongst this population, with distances $>5 \mathrm{~km}$ return trip for most households, and volumes of water available for drinking, cooking and hygiene were broadly low, as seen in much of DRC [87]. Hygiene kit distribution is only one part of response efforts to reduce transmission and incidence of disease. Inadequate or limited access to WASH infrastructure will affect cholera prevention and control efforts [6], and may have interacted with the effect of the hygiene kit intervention, while other potentially important transmission routes have been ignored. Environment-to-human transmission of cholera directly from contaminated water sources [88], contact with faeces in the environment or lack of sanitation [18], fly transmission [89, 90] and safe burial practices [91], were not targeted with the hygiene kit intervention.

\section{Successes of hygiene kit distribution}

Although several barriers limited the effectiveness of the overall intervention, it was noted that the intervention was well received by households that did receive the hygiene kit, and interviewed households were observed to and self-reported that demonstrations at the CTUs were clear and easy to understand. All components of the kit were used but in varying frequencies. Soap, jerrycans and the handwashing device were reportedly and observably used the most, and high adherence to using the handwashing device was reported in SSIs. Overall, hygiene kit distribution successfully translated to reported and observed improvements in household WASH knowledge and practices, as expected in the Outputs and Outcomes listed in the ToC.

Existing research has provided examples where both the kit and its components can reduce the incidence of cholera [24, 47-50, 92, 93]. With one study in Bangladesh finding cholera-specific hygiene promotion and hygiene kit distribution - a similar case-centred strategy to this MSF response- among admitted cases and households contacts leading to a $50 \%$ reduction in cholera incidence among household contacts of cases [25]. Although barriers to coverage and utility have been identified in this study, the hygiene kit may be an effective rapid and short-term measure in contexts such as DRC, particularly where longer-term WASH improvements are under-resourced [8], and targeting interventions to case households where risk of transmission is higher may thus be more efficient $[12-14,94]$.

\section{Limitations}

The distribution of hygiene kits was implemented as a programme, not a research study, and accordingly this left many factors of intervention delivery open to change and interpretation by the implementers, rather than under control of the study staff. Although this allowed for the process evaluation to reflect real-world conditions, it limits the ability to rigorously test and draw certain conclusions on what could be effective models for delivery and adoption of the intervention by the population. Evidence around the effectiveness of WASH interventions in cholera prevention and control is limited [24], particularly from emergency contexts [95], and although the results here show the distribution of kits is a feasible response in this setting, a true assessment of this intervention to reduce cholera transmission would require a more rigorous study design.

Another limitation of the study is the reflexivity and bias of the researchers. It is possible that as the researchers were MSF staff and working closely under intense conditions with the intervention team, the relationship between the enumerator and interviewees may have exacerbated bias in their interactions and/or their reporting of events. There are already numerous challenges noted from conducting research in humanitarian contexts $[95,96]$, but the close relationship of the evaluation team to the implementers and pressures of the context may have resulted in social desirability bias on the side of the interviewees and interviewer bias in the side of enumerators. Most data were self-reported, and saturation of the data was reached quickly in our study population, potentially due to reporter and social desirability bias. Households who were interviewed may also have been more likely to recall positive experiences 
to the MSF-related, and thus intervention-related, evaluation team, leading to an inflation of responses. It has also been argued that interviews and data collected on personal behaviours such as handwashing are often overestimated [45, 92].

Additionally, although a snapshot of the contextual events and influences have been captured during our study, it is difficult to both capture all events and influences that may impede or strengthen the effect of an intervention [93]. Our approach assumed a relatively stable relationship between context, implementation and participant response [97] and have taken a snapshot of one point in time. However, some of the identified factors may have existed prior to the intervention, or there may have been a dynamic relationship that emerged during implementation which does not capture the effect of the context on the programme $[50,98]$. The causal pathway of the relationship between the three domains of context, implementation and participant response may not be fully understood and this study design may not have provided the means to understand the process. Despite these limitations, the results of the study are informative, and we have triangulated across multiple data collection methods.

\section{Conclusions}

Hygiene kit distribution is a promising intervention for cholera control. The integration of a WASH intervention at the point of admission of suspected cases is new in cholera control efforts, particularly in outbreaks and complex emergencies. This study has shown that it is possible to distribute interventions from the HCF and employ case-centred WASH interventions. However, the programme we evaluated suffered from barriers to the timely supply, inadequate availability and consequent coverage of the hygiene kits. These issues warrant consideration in subsequent cholera responses, the development of new guidelines, training of new staff and integration of these findings in national and organisation-specific cholera control efforts. Further research is also required to identify ways to improve implementation and delivery of this promising intervention.

\section{Abbreviations \\ AR: Attack Rate; CFR: Case Fatality Rate; CHW: Community Health Worker; CTC: Cholera Treatment Centre; CTU: Cholera Treatment Unit; DRC: Democratic Republic of Congo; HCF: Health Care Facility; MSF: Médecins Sans Frontières; NGO: Non-Governmental Organisation; OCV: Oral Cholera Vaccination; ORP: Oral Rehydration Point; PNECHOL- MD: Programme National d'Elimination du Choléra et de Lutte contre les autres Maladies Diarrhéiques; POU: Point of Use; RRT: Rapid Response Teams; SSI: Semi-Structured Interview; ToC: Theory of Change; WASH: Water, Sanitation and Hygiene; W: Epidemiological Week}

\section{Acknowledgments}

We are grateful to the support of several colleagues who have engaged in the practical and academic aspects of this process evaluation both in DRC, Belgium and the UK. Thanks go to our enumerators: Jeannette Luthala,
Brunette Nakoka, Gaspard Tapo, Denis Lungi, Kalume Kalumwendo, Noel Mufumbele, and other members of the team including: Noè Kanyinda, Ali Luyeye, Marisel Méndez Yépez, Hilde Vochten, and the Pool d'Urgence Congo (PUC) from MSF DRC; to our translators: Paul Mukendi, Dieu Donne Kashala, Emmanuel Kayembe, Benoit Kabeya and Yvonne Tshibwaya; to our fleet of 20 motorcycle drivers in Kasaï-Oriental; to Pierre Pech, Damien Scarlett, Thierry Sakora, Ahmed Abd-Elrahman, Vincent Lambert, Emmanuel Lampaert from MSF Brussels; and to Robert Dreibelbis, Karl Blanchet, Adam Biran and Sandy Cairncross at LSHTM. Last but by no means least, we thank the participants and communities of Kasansa for volunteering for this study.

\section{Disclaimer}

The findings and conclusions in this report are those of the author(s) and do not necessarily represent the official position of the individuals involved or funding agency.

\section{Authors' contributions}

LDG conceived the study, and LDG and OC designed the study with input from RD, RVDB, PM and FC. SB contributed to the development of data collection tools and collected data during the intervention implementation. LDG, SB, AG and MM oversaw all data collection. LDG analysed the data with input from KG, FC and OC. LDG drafted the manuscript and all co-authors contributed revisions to the manuscript. LDG had final responsibility for the decision to submit for publication. All authors read and approved the final manuscript.

\section{Funding}

This study was funded by Médecins Sans Frontières. The funders of the study reviewed the study protocol but had no role in study design, data analysis or decision to publish.

\section{Availability of data and materials}

The datasets generated and/or analysed during the current study are available from the corresponding author on reasonable request.

\section{Ethics approval and consent to participate}

The study protocol was approved by the ethics board at the London School of Hygiene and Tropical Medicine (No. 14425) and by the School of Public Health at the University of Kinshasa, Democratic Republic of Congo (No. 67) CNES/BN/PMMF/2018). The ethics board at Médecins Sans Frontières also provided approval of a generic protocol for the study (No. 1805c). Written informed consent was obtained from all study participants. All consent forms were available in French, English and the local language of Tshiluba. Consent forms were provided in the language appropriate for the participant. Participant interviews were transcribed and de-identified. All data was kept confidential.

\section{Consent for publication}

Not applicable.

\section{Competing interests}

On behalf of all authors, there are no competing interests to declare that could be construed to have influenced the work. The authors alone are responsible for their views expressed in this article and they do not represent the views, decisions or policies of the institutions with which they are associated. Authors from MSF (SB, RD, MM, AG, DV, RVDB, and PM) contributed independently in their own rights as individuals.

\section{Author details}

${ }^{1}$ Faculty of Infectious and Tropical Diseases, London School of Hygiene and Tropical Medicine, London, UK. ${ }^{2}$ Environmental Health Unit, Médecins Sans Frontières, Brussels, Belgium. ${ }^{3}$ Médecins Sans Frontières, Kinshasa, Democratic Republic of Congo. ${ }^{4}$ LuxOR, Luxembourg Operational Research Unit, Médecins Sans Frontières, Luxembourg City, Luxembourg. ${ }^{5}$ Faculty of Epidemiology and Population Health, London School of Hygiene and Tropical Medicine, London, UK. 
Received: 21 May 2020 Accepted: 15 July 2020

Published online: 24 July 2020

\section{References}

1. Smith KF, Goldberg M, Rosenthal S, Carlson L, Chen J, Chen C, et al. Global rise in human infectious disease outbreaks. J R Soc Interface. 2014;11(101): 20140950.

2. WHO. Disease outbreaks archive 1996 to present. Available from: http:// www.who.int/csr/don/archive/year/en/. Accessed 12 Oct 2019.

3. Legros D, Partners of the Global Task Force on Cholera C. Global Cholera Epidemiology: Opportunities to Reduce the Burden of Cholera by 2030. J Infect Dis. 2018;218(suppl_3):S137-S40.

4. WHO. Cholera 2017. Wkly Epidemiol Rec. 2018;38(93):489-500.

5. Weill FX, Domman D, Njamkepo E, Tarr C, Rauzier J, Fawal N, et al. Genomic history of the seventh pandemic of cholera in Africa. Science. 2017; 358(6364):785-9.

6. Lessler J, Moore SM, Luquero FJ, MCKay HS, Grais R, Henkens M, et al. Mapping the burden of cholera in sub-Saharan Africa and implications for control: an analysis of data across geographical scales. Lancet. 2018; 391(10133):1908-15.

7. Bwire G, Mwesawina M, Baluku Y, Kanyanda SS, Orach CG. Cross-border cholera outbreaks in sub-Saharan Africa, the mystery behind the silent illness: what needs to be done? PLoS One. 2016;11(6):e0156674.

8. Ingelbeen B, Hendrickx D, Miwanda B, van der Sande MAB, Mossoko M, Vochten $\mathrm{H}$, et al. Recurrent cholera outbreaks, Democratic Republic of the Congo, 2008-2017. Emerg Infect Dis. 2019;25(5):856-64.

9. Cholera Platform. Cholera outbreaks in central and West Africa cholera: 2018 updates week 52. 2017.

10. Bompangue D, Giraudoux P, Piarroux M, Mutombo G, Shamavu R, Sudre B, et al. Cholera epidemics, war and disasters around Goma and Lake Kivu: an eight-year survey. PLoS Negl Trop Dis. 2009;3(5):e436.

11. Cholera Platform. Cholera outbreaks in central and West Africa cholera: 2018 updates week 50. 2018.

12. Sugimoto JD, Koepke AA, Kenah EE, Halloran ME, Chowdhury F, Khan Al, et al. Household transmission of Vibrio cholerae in Bangladesh. PLoS Negl Trop Dis. 2014;8(11):e3314.

13. Weil AA, Begum Y, Chowdhury F, Khan Al, Leung DT, LaRocque RC, et al. Bacterial shedding in household contacts of cholera patients in Dhaka, Bangladesh. Am J Trop Med Hyg. 2014;91(4):738-42.

14. Bi Q, Azman AS, Satter SM, Khan Al, Ahmed D, Riaj AA, et al. Micro-scale spatial clustering of cholera risk factors in urban Bangladesh. PLoS Negl Trop Dis. 2016;10(2):e0004400.

15. Weil AA, Khan Al, Chowdhury F, Larocque RC, Faruque AS, Ryan ET, et al. Clinical outcomes in household contacts of patients with cholera in Bangladesh. Clin Infect Dis. 2009;49(10):1473-9.

16. Spira WM, Khan MU, Saeed YA, Sattar MA. Microbiological surveillance of intra-neighbourhood E1 Tor cholera transmission in rural Bangladesh. Bull World Health Organ. 1980;58(5):731-40

17. Mosley WH, Benenson AS, Barui R. The relationship of vibriocidal antibody titre to susceptibility to cholera in family contacts of cholera patients. Bull World Health Organ. 1968;38(3):335-46.

18. Wolfe M, Kaur M, Yates T, Woodin M, Lantagne D. A systematic review and meta-analysis of the association between water, sanitation, and hygiene exposures and cholera in case-control studies. Am J Trop Med Hyg. 2018; 99(2):534-45.

19. Richterman A, Sainvilien DR, Eberly L, Ivers LC. Individual and Household Risk Factors for Symptomatic Cholera Infection: A Systematic Review and Meta-analysis. J Infect Dis. 2018;218(suppl_3):S154-S64.

20. Harris JB, LaRocque RC, Qadri F, Ryan ET, Calderwood SB. Cholera. Lancet. 2012;379(9835):2466-76.

21. Mukandavire Z, Morris JG. Modeling the Epidemiology of Cholera to Prevent Disease Transmission in Developing Countries. Microbiol Spectr. 2015;3(3). https://doi.org/10.1128/microbiolspec.VE-0011-2014.

22. Fung IC. Cholera transmission dynamic models for public health practitioners. Emerg Themes Epidemiol. 2014;11(1):1.

23. Codeço CT. Endemic and epidemic dynamics of cholera: the role of the aquatic reservoir. BMC Infect Dis. 2001;1:1

24. Taylor DL, Kahawita TM, Cairncross S, Ensink JH. The impact of water, sanitation and hygiene interventions to control cholera: a systematic review. PLoS One. 2015;10(8):e0135676.
25. George CM, Monira S, Sack DA, Rashid MU, Saif-Ur-Rahman KM, Mahmud T, et al. Randomized controlled trial of hospital-based hygiene and water treatment intervention (CHoBl7) to reduce cholera. Emerg Infect Dis. 2016; 22(2):233-41.

26. D'Mello-Guyett L, Gallandat K, Van den Bergh R, Taylor D, Bulit G, Legros D, et al. Prevention and control of cholera with household and community water, sanitation and hygiene (WASH) interventions: a scoping review of current international guidelines. PLoS One. 2020;15(1):e0226549.

27. von Seidlein L, Deen JL. Preventing cholera outbreaks through early targeted interventions. PLoS Med. 2018;15(2):e1002510.

28. Rebaudet S, Bulit G, Gaudart J, Michel E, Gazin P, Evers C, et al. The casearea targeted rapid response strategy to control cholera in Haiti: a four-year implementation study. PLoS Negl Trop Dis. 2019:13(4):e0007263.

29. Finger F, Bertuzzo E, Luquero FJ, Naibei N, Touré B, Allan M, et al. The potential impact of case-area targeted interventions in response to cholera outbreaks: a modeling study. PLoS Med. 2018;15(2):e1002509.

30. MSF. Management of a Cholera Epidemic. Médecins Sans Frontières; 2017.

31. UNICEF. Cholera Toolkit. New York: United Nations Children's Fund; 2013.

32. ACF. Manuel Pratique: Eau, Assainissement, Hygiène dans la Lutte Contre le Choléra. Paris: Action Contre la Faim; 2013.

33. Oxfam. Cholera Outbreak Guidelines: Preparedness, Prevention and Control. Oxford: Oxfam; 2012

34. The Sphere Handbook. Humanitarian Charter and Minimum Standards in Humanitarian Response. Geneva: Sphere Association; 2018.

35. Lantagne D, Yates T. Household Water Treatment and Cholera Control. J Infect Dis. 2018;218(suppl_3):S147-S53.

36. Gartley M, Valeh P, de Lange R, Dicarlo S, Viscusi A, Lenglet A, et al. Uptake of household disinfection kits as an additional measure in response to a cholera outbreak in urban areas of Haiti. J Water Health. 2013;11(4):623-8.

37. Briere EC, Ryman TK, Cartwright E, Russo ET, Wannemuehler KA, Nygren BL, et al. Impact of integration of hygiene kit distribution with routine immunizations on infant vaccine coverage and water treatment and handwashing practices of Kenyan mothers. J Infect Dis. 2012;205(Suppl 1):S56-64.

38. Parker AA, Stephenson R, Riley PL, Ombeki S, Komolleh C, Sibley L, et al. Sustained high levels of stored drinking water treatment and retention of hand-washing knowledge in rural Kenyan households following a clinicbased intervention. Epidemiol Infect. 2006;134(5):1029-36.

39. Peterson EA, Roberts L, Toole MJ, Peterson DE. The effect of soap distribution on diarrhoea: Nyamithuthu refugee camp. Int J Epidemiol. 1998;27(3):520-4.

40. Yates T, Vujcic JA, Joseph ML, Gallandat K, Lantagne D. Water, sanitation, and hygiene interventions in outbreak response: a synthesis of evidence. Waterlines. 2018;37(1):5-30.

41. Yates T, Allen J, Joseph M, Lantagne D. Short-term WASH interventions in emergency response: a systematic review. London: International Initative for Impact Evaluation (3ie); 2017.

42. Bompangue D, Moore S, Taty N, Impouma B, Sudre B, Manda R, et al. Description of the targeted water supply and hygiene response strategy implemented during the cholera outbreak of 2017-2018 in Kinshasa, DRC. BMC Infect Dis. 2020:20(1):226.

43. D'Mello-Guyett L, Yates T, Bastable A, Dahab M, Deola C, Dorea C, et al. Setting priorities for humanitarian water, sanitation and hygiene research: a meeting report. Confl Health. 2018;12:22. https://doi.org/10.1186/s13031-018-0159-8.

44. Brown J, Clasen T. High adherence is necessary to realize health gains from water quality interventions. PLoS One. 2012;7(5):e36735.

45. Freeman MC, Stocks ME, Cumming $\mathrm{O}$, Jeandron A, Higgins JP, Wolf J, et al. Hygiene and health: systematic review of handwashing practices worldwide and update of health effects. Tropical Med Int Health. 2014;19(8):906-16.

46. Hutton $\mathrm{G}$, Chase C. The Knowledge Base for Achieving the Sustainable Development Goal Targets on Water Supply, Sanitation and Hygiene. Int J Environ Res Public Health. 2016;13(6):536.

47. UK Medical Research Council. Process evaluations of complex interventions. UK: MRC Population Health Sciences Research Network; 2011.

48. Carroll C, Patterson M, Wood S, Booth A, Rick J, Balain S. A conceptual framework for implementation fidelity. Implement Sci. 2007:2:40.

49. Pfadenhauer LM, Gerhardus A, Mozygemba K, Lysdahl KB, Booth A, Hofmann B, et al. Making sense of complexity in context and implementation: the context and implementation of complex interventions (ClCl) framework. Implement Sci. 2017;12(1):21.

50. Murdoch J. Process evaluation for complex interventions in health services research: analysing context, text trajectories and disruptions. BMC Health Serv Res. 2016;16(1):407. 
51. Bonell C, Oakley A, Hargreaves J, Strange V, Rees R. Assessment of generalisability in trials of health interventions: suggested framework and systematic review. BMJ. 2006;333(7563):346-9.

52. Grant A, Treweej S, Dreischulte T, Foy R, Guthrie B. Process evaluations for cluster-randomised trials of complex interventions: a proposed framework for design and reporting. Trials. 2013;14:15.

53. De Silva MJ, Breuer E, Lee LA, Asher L, Chowdhary N, Lund C, et al. Theory of change: a theory-driven approach to enhance the Medicial research Council's framework for complex interventions. Trials. 2014;15:267.

54. MSF. Terms of Reference for Assessment and Response Justification: Kasansa Cholera Outbreak. Mbuji-Mayi, Kasaï-Oriental: Pool d'Urgence, MSF DRC; 2018.

55. PNECHOL-MD. Situation épidémiologique du choléra en RDC à la Semaine 28 (09-15 Juillet 2018). Kinshasa: Ministère de la Santé; 2018.

56. MSF. Rapport Epidemio Evaluation Kasansa: Description de l'epidemic de cholera dans la Zone de Santé Kasansa Mbuji-Mayi. Kasaï-Oriental: Pool d'Urgence, MSF DRC; 2018.

57. Cholera Platform. Cholera outbreaks in central and West Africa cholera: 2018 updates week 34. 2018.

58. PNECHOL-MD. Situation épidémiologique du choléra en RDC à la Semaine 35 (27 Août - 2 Septembre 2018). Kinshasa: Ministère de la Santé; 2018.

59. WASH Cluster. Reunion de Cluster WASH- Mbuji Mayi, S41. Mbuji Mayi, Kasaï-Oriental; 2018.

60. PNECHOL-MD. Situation épidémiologique du choléra en RDC à la Semaine 38 (17-23 Septembre 2018). Kinshasa: Ministère de la Santé; 2018.

61. PNECHOL-MD. Situation épidémiologique du choléra en RDC à la Semaine 33 (13-19 Août 2018). Kinshasa: Ministère de la Santé; 2018.

62. PNECHOL-MD. Situation épidémiologique du choléra en RDC à la Semaine 32 (6-12 Août 2018). Kinshasa: Ministère de la Santé; 2018.

63. PNECHOL-MD. Situation épidémiologique du choléra en RDC à la Semaine 29 (16-22 Juillet 2018). Kinshasa: Ministère de la Santé; 2018.

64. PNECHOL-MD. Situation épidémiologique du choléra en RDC à la Semaine 30 (23-29 Juillet 2018). Kinshasa: Ministère de la Santé; 2018.

65. WASH Cluster. Reunion de Cluster WASH- Mbuji Mayi, S46. Mbuji Mayi, Kasaï-Oriental; 2018.

66. MSF. Rapport Medical Fin Intervention Cholera ZS Kasansa. Kinshasa; 2018.

67. Cholera Platform. Cholera Outbreaks in Central and West Africa Cholera: 2017 Annual Highlights 2017.

68. MSF. DRC: Fighting the Country's Worst Cholera Epidemic in Decades 2018 Available from: http://www.doctorswithoutborders.org/article/drc-fightingcountry\%E2\%80\%99s-worst-cholera-epidemic-decades.

69. Greenland K, Chipungu J, Chilekwa J, Chilengi R, Curtis V. Disentangling the effects of a multiple behaviour change intervention for diarrhoea control in Zambia: a theory-based process evaluation. Glob Health. 2017;13(1):78.

70. Hargreaves JR, Goodman C, Davey C, Willey BA, Avan BI, Schellenberg JR. Measuring implementation strength: lessons from the evaluation of public health strategies in low- and middle-income settings. Health Policy Plan. 2016;31(7):860-7.

71. Craig P, Petticrew M. Developing and evaluating complex interventions: reflections on the 2008 MRC guidance. Int J Nurs Stud. 2013;50(5):585-7.

72. Murdoch J, Curran R, Bachmann M, Bateman E, Cornick RV, Doherty T, et al. Strengthening the quality of paediatric primary care: protocol for the process evaluation of a health systems intervention in South Africa. BMJ Glob Health. 2018;3(Suppl 5):e000945.

73. Tong A, Sainsbury P, Craig J. Consolidated criteria for reporting qualitative research (COREQ): a 32-item checklist for interviews and focus groups. Int Qual Health Care. 2007;19(6):349-57.

74. MSF. In: Medecins Sans Frontieres, editor. Kit Catalogue; 2017.

75. Flemming K, Booth A, Garside R, Tuncalp O, Noyes J. Qualitative evidence synthesis for complex interventions and guideline development: clarification of the purpose, designs and relevant methods. BMJ Glob Health. 2019; 4(Suppl 1):e000882.

76. Booth A, Noyes J, Flemming K, Moore G, Tuncalp O, Shakibazadeh E. Formulating questions to explore complex interventions within qualitative evidence synthesis. BMJ Glob Health. 2019:4(Suppl 1):e001107.

77. MSF. MSF en RDC. Kinshasa: Médecins Sans Frontières; 2017.

78. Roskosky M, Acharya B, Shakya G, Karki K, Sekine K, Bajracharya D, et al. Feasibility of a comprehensive targeted cholera intervention in the Kathmandu Valley, Nepal. Am J Trop Med Hyg. 2019;100(5):1088-97.

79. Villeminot N. Strengthening market systems that provide water and hygiene items for cholera mitigation and emergency preparedness in Haiti. Waterlines. 2018;37(4):307-18.
80. Watson J, Dreibelbis R, Aunger R, Deola C, King K, Long S, et al. Child's play: harnessing play and curiosity motives to improve child handwashing in a humanitarian setting. Int J Hyg Environ Health. 2019;222(2):177-82.

81. White $\mathrm{S}$, Thorseth $\mathrm{AH}$, Dreibelbis $\mathrm{R}$, Curtis $\mathrm{V}$. The determinants of handwashing behaviour in domestic settings: an integrative systematic review. Int J Hyg Environ Health. 2020;227:113512.

82. Ali M, Nelson AR, Lopez AL, Sack DA. Updated global burden of cholera in endemic countries. PLoS Negl Trop Dis. 2015;9(6):e0003832.

83. Arnold BF, Colford JM Jr. Treating water with chlorine at point-of-use to improve water quality and reduce child diarrhea in developing countries: a systematic review and meta-analysis. Am J Trop Med Hyg. 2007;76(2):354-64.

84. George CM, Jung DS, Saif-Ur-Rahman KM, Monira S, Sack DA, Mahamud-ur $\mathrm{R}$, et al. Sustained uptake of a hospital-based Handwashing with soap and water treatment intervention (cholera-hospital-based intervention for 7 days [CHoBI7]): a randomized controlled trial. Am J Trop Med Hyg. 2016:94(2): 428-36

85. Vujcic J, Ram P, Blum L. Handwashing promotion in humanitarian emergencies: strategies and challenges according to experts. Water, Sanitation and Hygiene for Development. 2015;5(4):574-85.

86. Stelmach RD, Clasen T. Household water quantity and health: a systematic review. Int J Environ Res Public Health. 2015;12(6):5954-74.

87. Jeandron A, Saidi JM, Kapama A, Burhole M, Birembano F, Vandevelde T, et al. Water supply interruptions and suspected cholera incidence: a timeseries regression in the Democratic Republic of the Congo. PLoS Med. 2015; 12(10):e1001893.

88. Bombangue D, Giraudoux $P$, Handschumer $P$, Piarroux M, Sudre B, Ekwanzala $M$, et al. Lakes as source of cholera outbreaks, Democratic Republic of Congo. Emerg Infect Dis. 2008;14(5):798-800.

89. Macrae R. Flies and cholera diffusion. Ind Med Gaz. 1894;29(11):407-12.

90. Yap KL, Kalpana M, Lee HL. Wings of the common house fly (Musca domestica L.): importance in mechanical transmission of Vibrio cholerae. Trop Biomed. 2008;25(1):1-8.

91. Gunnlaugsson G, Einarsdottir J, Angulo FJ, Mentambanar SA, Passa A, Tauxe RV. Funerals during the 1994 cholera epidemic in Guinea-Bissau, West Africa: the need for disinfection of bodies of persons dying of cholera. Epidemiol Infect. 1998;120(1):7-15.

92. Contzen N, De Pasquale S, Mosler HJ. Over-reporting in Handwashing selfreports: potential explanatory factors and alternative measurements. PLoS One. 2015;10(8):e0136445.

93. Moore G, Audrey S, Barker M, Bond L, Bonell C, Cooper C, et al. Process evaluation in complex public health intervention studies: the need for guidance. J Epidemiol Community Health. 2014;68(2):101-2.

94. Debes AK, Ali M, Azman AS, Yunus M, Sack DA. Cholera cases cluster in time and space in Matlab, Bangladesh: implications for targeted preventive interventions. Int J Epidemiol. 2016;45(6):2134-9.

95. Ramesh A, Blanchet K, Ensink JH, Roberts B. Evidence on the effectiveness of water, sanitation, and hygiene (WASH) interventions on health outcomes in humanitarian crises: a systematic review. PLoS One. 2015;10(9):e0124688.

96. Ager A, Burnham G, Checchi F, Gayer M, Grais RF, Henkens M, et al. Strengthening the evidence base for health programming in humanitarian crises. Science. 2014;345(6202):1290-2.

97. Bonell C, Warren E, Fletcher A, Viner R. Realist trials and the testing of context-mechanism-outcome configurations: a response to Van belle et al. Trials. 2016;17(1):478

98. Vousden N, Lawley E, Seed PT, Gidiri MF, Charantimath U, Makonyola G, et al. Exploring the effect of implementation and context on a steppedwedge randomised controlled trial of a vital sign triage device in routine maternity care in low-resource settings. Implement Sci. 2019;14(1):38.

\section{Publisher's Note}

Springer Nature remains neutral with regard to jurisdictional claims in published maps and institutional affiliations. 